\title{
Bilateral spatial summation of cooling of symmetrical sites
}

\author{
ANDREW J. RÓZSA and DAN R. KENSHALO \\ Department of Psychology and The Psychobiology Research Center \\ Florida State University, Tallahassee, Florida 32306
}

\begin{abstract}
The possibility of spatial summation of conducted $-\Delta \mathrm{Ts}$ (temperature decrements from the adapted skin temperature) was tested when the $-\Delta$ Ts were presented simultaneously and individually at symmetrical sites on either side of the body. The use of a signal detection rating method yielded data that indicate that spatial summation is complete (area and intensity trade reciprocally) for $-\Delta s$ near threshold and at clearly suprathreshold intensities of stimulation is invariant of the adapted skin temperature (AT), and the intensity of stimulation within the range of stimuli used (from as little as $-0.05^{\circ} \mathrm{C}$ to as much as $-1.25^{\circ} \mathrm{C}$ ). In view of the characteristics ascribed to the thermosensory apparatus in humans, it is postulated that spatial summation occurs in the central nervous system.
\end{abstract}

Based primarily upon psychophysical measurements of human temperature sensitivity, several variables of thermal stimulation are of primary importance (Kenshalo, 1972). These are: (a) the initial (adapted) skin temperature; (b) the intensity of the temperature change from the adapted skin temperature; (c) the rate of the temperature change; (d) the body site being stimulated; and (e) the area of the skin surface that is stimulated (spatial summation). Of these, the last, spatial summation, is the subject of this investigation.

Hardy and Oppel (1937) showed that $+\Delta T$ s (temperature increments from normal skin temperature) summate extensively - so much so that at threshold the intensity of the stimulus and its spatial extent can trade almost reciprocally. While many of the earlier studies investigated spatial summation at threshold, more recent ones show that the effect of spatial summation of $+\Delta T$ s becomes progressively smaller with increased stimulus intensities (Marks, 1971; Marks \& Stevens, 1973; Stevens \& Marks, 1971). The amount of summation of $+\Delta T s$ appeared to decrease as the area stimulated increased in size, an observation also made by Herget, Granath, and Hardy (1941).

Not only does spatial summation of $+\Delta T$ s occur at single sites of increasing area, but it also occurs when two sites, symmetrically located on opposite sides of the body, are simultaneously stimulated. Hardy and Oppel (1937) found that the threshold for $+\Delta T$ s was lower when the backs of the two hands were simultaneously stimulated than when either

Submitted to the faculty of the Department of Psychology in partial fulfillment of the requirements for a Masters of Science degree in Psychology. This research was supported by PHS Grant NS-02992. hand was stimulated alone. Spatial summation was not observed when the forehead and the contralateral hand were simultaneously stimulated. Similar observations have been made for sites on either side of the midline of the forehead (Marks \& Stevens, 1973) and between dermatomes on the back (Banks, 1973). These results do not completely exclude the possibility that a peripheral neural mechanism is involved in spatial summation at single sites of $+\Delta \mathrm{T}$ stimulation. They are regarded, however, as a demonstration that a central nervous system mechanism is involved.

While there are data that show the manner in which $+\Delta$ Ts at both threshold and suprathreshold intensities exhibit spatial summation, there is a dearth of information about spatial summation of - $\Delta$ Ts perhaps due to technical difficulties in producing adequate and well-controlled stimuli. In the single study seen on this topic, Hardy and Oppel (1938) found that threshold $-\Delta$ Ts show spatial summation at single sites but to a lesser degree than for $+\Delta \mathrm{Ts}$.

We believe that a better understanding of the thermal senses will be realized if the two sensations, cool and warm, are considered as separate modalities. First, the sensations associated with warm and cool stimuli are different (Kenshalo, 1970). The "onset" of a warm sensation feels slow and "blooms" while cool sensations feel quick and sharp. Differences have been found in the exponents of the psychophysical power functions for the two sensations (Stevens \& Stevens, 1960), and in the physical distribution of "cold" and "warm" spots on the skin (Dallenbach, 1927). Second, in view of some of the electrophysiological studies of the last three decades, we can be certain that the receptors are different (Hensel, 1973). Separate primary fiber 
systems (Dodt \& Zotterman, 1952; Hensel \& Zotterman, 1951) via unknown central pathways appear to terminate differentially on segregated cortical cells (Kreisman \& Zimmerman, 1973; Chatt, Note 1). These considerations lead us to conclude that the rules that govern the operation of one sensation may not apply equally well to the other.

In the present investigation, $-\Delta T$ s were presented either singly or simultaneously to the volar forearms and the observer was asked to rate his confidence that a stimulus had been presented. The results show that complete bilateral summation of $-\Delta$ Ts occurs and, based on this and other evidence, we conclude that a central mechanism is required to account for the spatial summation of $-\Delta \mathrm{T}$ s.

\section{METHOD}

\section{Subjects}

The paid subjects were three males, between 20 and 26 years of age, with experience in making thermal discriminations in the experimental paradigm. They received at least $10 \mathrm{~h}$ of pretest training in the experimental situation.

\section{Apparatus}

The subjects were seated comfortably in a modified dental chair located in a constant temperature-humidity room. The arms of the chair were modified so that both volar forearms of the subjects rested flatly against the floors of Plexiglas armrests. Thermal stimulators (thermodes) with functional surfaces of $18.4 \mathrm{~cm}^{2}$ were nested in Plexiglas housings on the floors of the armrests. Since they protruded approximately $2 \mathrm{~mm}$ above the floor levels, they fully contacted the volar surfaces of the forearms approximately $19 \mathrm{~cm}$ from the wrist.

The thermal stimuli were delivered by means of two thermodes (Peltier devices) (Kenshalo \& Bergen, 1975). These thermodes maintained constant skin temperatures, within the physiological range, with an accuracy of $\pm 0.001^{\circ} \mathrm{C}$, and controls were provided for changing the temperature in either direction by predetermined amounts from as little as $0.01^{\circ} \mathrm{C}$ to as much as $10^{\circ} \mathrm{C}$, at rates from $0.04^{\circ}$ to $2^{\circ} \mathrm{C} / \mathrm{sec}$ with an accuracy of $0.01^{\circ} \mathrm{C}$ or 1 percent, whichever is greater. Since the operation of the thermode was entirely electrical, no cues other than the temperatures changes were present.

The dental chair and the thermodes were located in the constant temperature-humidity room, and the current control and programming equipment were located in an adjacent room. Continuous two-way communication between the experimenter and the subjects was maintained by the intercom system.

\section{Procedure}

The subjects were seated in the dental chair as comfortably as possible and rested their forearms and hands flatly against the armrests. Proper adjustments were made for comfort depending on the subject's forearm length and height, and thickness of the wrists. They were then given $10 \mathrm{~min}$ to adapt to a preset adapting temperature (AT). Written and verbal instructions informed the subjects that in each trial they had to decide whether they could detect a temperature change, and their confidence in the decision had to be reported as numbers called out to the experimenter. Thus, $1=$ "I am sure that $I$ did not feel a temperature change"; 2 = "I do not think I felt a temperature change, but I am not sure"; $3=$ "I think I felt a temperature change, but I am not sure"; and $4=$ "I am sure that I felt a temperature change."

Each trial was divided into three segments: warning, observation, and verbal answer periods. Each of these segments was commanded by the logic system and was displayed in the form of indicator lights on both the control panel and the subjects' indicator panel. Following the START command, a green light indicated the warning segment that lasted for 2,3 , or $4 \mathrm{sec}$, governed by an internal random signal generator. Concomitantly with the green light, an auditory signal also provided warning. At the end of this segment, both the green light and the auditory signal went off and a red light came on to indicate the observation segment of $3 \mathrm{sec}$ duration. A probability generator set to a probability of 0.50 determined whether or not $a-\Delta T$ occurred during this segment. When the red light went off, a white light came on to signal the verbal report segment. This segment was of $1 \mathrm{sec}$ duration, after which a new trial was automatically initiated by the programming equipment. During the report segment, the subjects rated their confidence of the presence of a stimulus via the intercom system. Four-digit counters kept a continuous record of the total number of trials, the number of trials with stimuli, and the number of each confidence rating reported.

Since thermal thresholds are markedly affected by the AT (Kenshalo, 1970), we wished to determine if spatial summation was also affected by the AT. Five ATs were used: $24^{\circ}, 28^{\circ}, 32^{\circ}$, $36^{\circ} \mathrm{C}$, and $40^{\circ} \mathrm{C}$. Furthermore, since spatial summation of $+\Delta \mathrm{Ts}$ has been shown to decrease as the stimulus intensity increased, three intensities of $-\Delta T$ s were used in this study. Intensities for near-"threshold" - $\Delta$ Ts were determined for each subject as a new $A T$ was introduced. Two more $-\Delta T$ intensities of twice and four times the lowest intensity were also used. All intensities were presented at a rate of $1{ }^{\circ} \mathrm{C} / \mathrm{sec}$.

A complete session consisted of the adaptation period plus three blocks of approximately equal numbers of trials. Each block lasted approximately $25 \mathrm{~min}$, separated by a 5 -min rest period, for a total of 500 scored trials and a session duration of approximately $95 \mathrm{~min}$.

During a session, one $-\Delta T$ intensity was presented at one AT under one of four conditions. These conditions were: (1) $L$, left forearm stimulated alone; (2) $R$, right forearm stimulated alone; (3) RL, both forearms stimulated simultaneously, the subject attending to the left forearm only; (4) LR, both forearms stimulated simultaneously, the subject attending to the right forearm only.

The subject's attention was directed to one or the other arm during stimulation of both arms in order to permit a control for possible differences in sensitivity of the two arms. An attempt was made to insure attention to the proper arm by inserting unscored "catch" trials at random intervals during the session. These were in addition to the scored 250 trials without and the 250 trials with stimulation called for by the signal detection paradigm, making a total of 550 scored and unscored trials during each session. The catch trials consisted of presenting the $\Delta \mathrm{T}$ only to the arm opposite that to which the subject was instructed to attend. The subjects never reported the detection of these $\Delta T$ s during sessions in which both forearms were stimulated.

Each subject served through the four main conditions. Each condition was repeated for three $-\Delta T$ intensities at the five ATs for a total of 60 sessions spread over a period of 12 weeks.

\section{Data Analysis}

Following the collection of data, each boundary between adjacent categories of confidence was treated as if it were the dividing line between "yes" and "no." The four response categories therefore yielded three pairs of operating probabilities from a session. Calculation and plotting of operating characteristics (OCs) were performed by a DEC PDP-12 laboratory computer that was programmed to plot the operating probabilities as standardized normal deviates and to compute the regression lines that best fitted the data points using the least squares method for each condition (Figure 1). Although the conventional least squares fit has been questioned as an appropriate curve-fitting procedure (Ogilvie \& Creelman, 1968), it was 


\section{OF FALSE ALARMS}

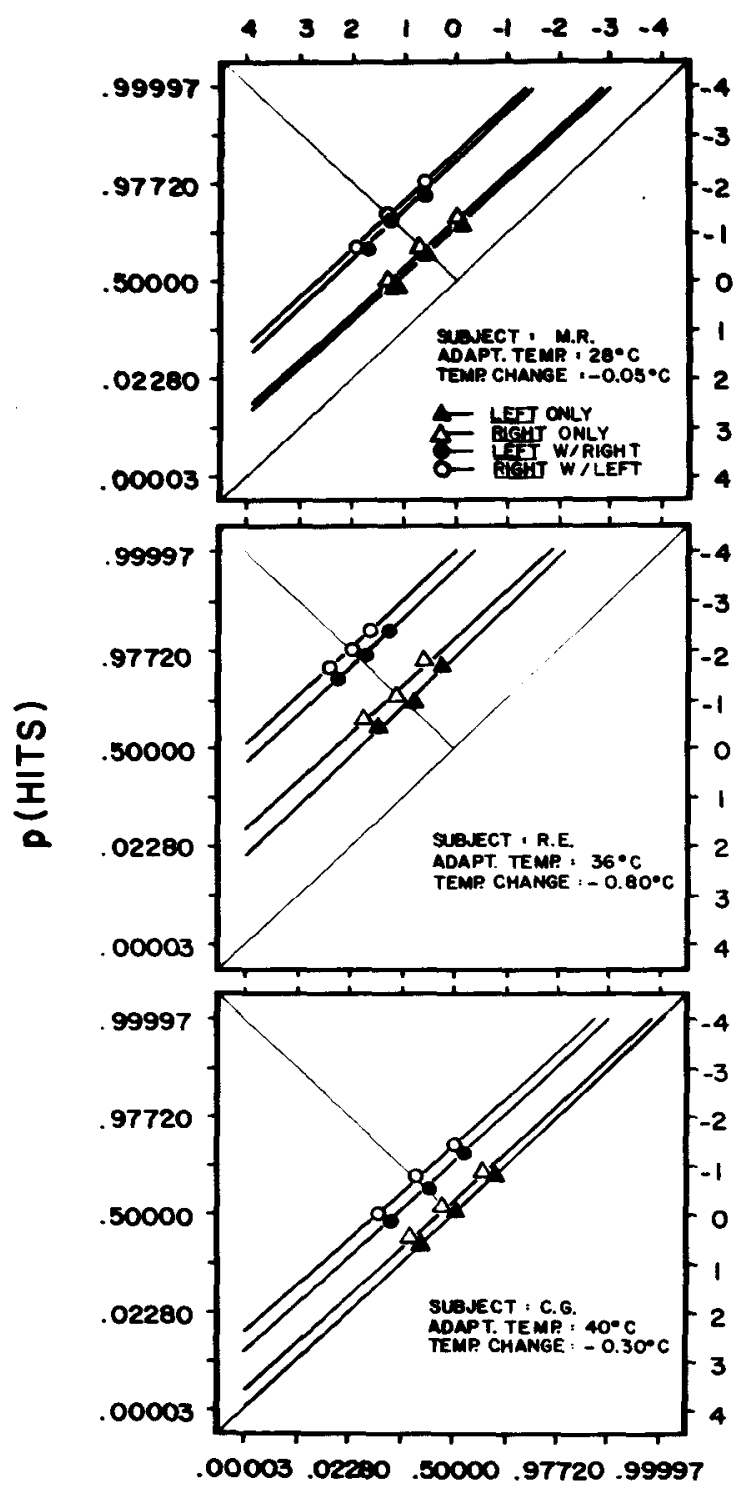

p(FALSE ALARMS)

where $d_{n}{ }^{\prime}$ is that predicted for the two-forearm condition and $\mathrm{d}_{i}{ }^{\prime}$ are the observed values for each forearm stimulated individually. Application of this model requires the assumption that in the two-forearm condition the individual observations are statistically independent, the observations are combined with no loss of information, and each observation is normally distributed with equal variances under the noise and the noise-plus-signal conditions. Rejection of the hypothesis requires that the observed d's for the two-forearm condition be statistically significantly larger than those predicted by the model.

\section{RESULTS}

It can be assumed that the calculations of d's were good approximations of detectability, since the data points used to generate OCs, while not independent, support an equal-variance Gaussian model; the mean slopes were almost equal to unity (mean of $0.97 \pm 0.09$, with a range from 0.87 to 1.11 for all 180 OCs).

Analyses of the data showed that the forearms differed in sensitivity. A parametric significance test (Gourevitch \& Galanter, 1967) for differences between the isosensitivity functions for the left forearm vs. the right forearm yielded statistically significant dextral superiority in detection (example in Table 1). Out of the 90 comparisons, 78 showed a larger detectability index for right than for left (even for the sinistral subject). A nonparametric binomial test also rejected the null hypothesis that the two forearms were equally sensitive $\left[\mathrm{B}^{*}=6.96>\mathrm{z}_{(.0002)}\right.$ ] (Hollander $\&$ Wolfe, 1973). This differential sensitivity introduced the possibility that separate analyses would be necessary for the two sides of the body. Table 2 illustrates, however, that the data from the two sides of the body can be averaged, because the Gourevitch and Galanter test showed that the magnitude of the differences between the two-forearm and the oneforearm condition for a given stimulus intensityadapting temperatures series were the same for each side of the body and for the averages as well. Thus,

$$
\begin{aligned}
& \left(d^{\prime}{ }_{R L}-d_{L}{ }^{\prime}\right) \cong\left(d_{L R}{ }^{\prime}-d_{R}{ }^{\prime}\right) \\
& \cong\left[\left(d_{R L^{\prime}}+d_{L R^{\prime}}\right) / 2-\left(d_{L}{ }^{\prime}+d_{R}{ }^{\prime}\right) / 2\right]
\end{aligned}
$$

Figure 1. Examples of best fit approximations for the operating characteristics (OCs) using normal-normal coordinates.

considered adequate for our purposes (Pastore \& Scheirer, 1974).

The finding of simply a greater sensitivity for the two than for the single forearm condition does not necessarily establish the existence of spatial summation. If it is assumed that the two forearms are independent detectors, simple statistical considerations predict a larger sensitivity index for the two than for the single forearm condition, even without any spatial summation.

In order to test the hypothesis that the two forearms are independent detectors, d's for the two forearm condition were predicted by the integration model of Green and Swets (1966) from the $d$ 's measured for the single forearm conditions, in which

$$
d_{n}^{\prime}=\left[\sum_{i=1}^{n}\left(d_{i}{ }^{\prime}\right)^{2 / 2},\right.
$$

These averaged data, therefore, were compared for each subject at each $-\Delta T$ across all ATs (Figure 2).

It is apparent that in all cases the detectability for the two-forearm condition was better than that for the single-forearm condition. However, the original hypothesis assumed the possibility that the two forearms were independent detectors and, when stimulated together, the individual observations of the forearms would be combined to yield d's larger than the ones obtained for either forearm alone. As can be seen in Figure 2, the d's obtained for the two-forearm conditions consistently exceeded, by statistically significant amounts, the d's predicted by Green and Swets' (1966) integrative model. Therefore, we reject the 
Table 1

Assessment of Significance of the Difference Between the Sensitivity Indices of Left and Right Forearms for Subject M.R. at AT $=40^{\circ} \mathrm{C}$

\begin{tabular}{|c|c|c|c|c|c|c|c|c|}
\hline \multirow[b]{3}{*}{$\begin{array}{c}\text { Temperature } \\
\text { Change }\end{array}$} & \multirow[b]{3}{*}{ Condition } & \multirow{2}{*}{\multicolumn{2}{|c|}{ Probability }} & \multicolumn{2}{|c|}{ Trials } & \multirow[b]{3}{*}{$\mathrm{d}^{\prime}$} & \multirow[b]{3}{*}{ Variance } & \multirow[b]{3}{*}{ G Test } \\
\hline & & & & & Without & & & \\
\hline & & $\begin{array}{c}\text { Correct } \\
\text { Rejection }\end{array}$ & Misses & $\begin{array}{l}\text { With Stimu- } \\
\text { lation }\end{array}$ & $\begin{array}{l}\text { Stimu- } \\
\text { lation }\end{array}$ & & & \\
\hline$-0.4^{\circ} \mathrm{C}$ & $\begin{array}{l}\text { Left } \\
\text { Right }\end{array}$ & $\begin{array}{l}.664 \\
.787\end{array}$ & $\begin{array}{l}.244 \\
.203\end{array}$ & $\begin{array}{l}250 \\
249\end{array}$ & $\begin{array}{l}250 \\
251\end{array}$ & $\begin{array}{l}1.11 \\
1.62\end{array}$ & $\begin{array}{l}.007 \\
.008\end{array}$ & $4.22 *$ \\
\hline$-0.2^{\circ} \mathrm{C}$ & $\begin{array}{l}\text { Left } \\
\text { Right }\end{array}$ & $\begin{array}{l}.669 \\
.720\end{array}$ & $\begin{array}{l}.357 \\
.289\end{array}$ & $\begin{array}{l}248 \\
254\end{array}$ & $\begin{array}{l}252 \\
246\end{array}$ & $\begin{array}{l}0.80 \\
1.13\end{array}$ & $\begin{array}{l}.007 \\
.007\end{array}$ & $2.86 *$ \\
\hline$-0.1^{\circ} \mathrm{C}$ & $\begin{array}{l}\text { Left } \\
\text { Right }\end{array}$ & $\begin{array}{l}.630 \\
.623 \\
\end{array}$ & $\begin{array}{l}.518 \\
.403\end{array}$ & $\begin{array}{l}257 \\
247\end{array}$ & $\begin{array}{l}243 \\
253\end{array}$ & $\begin{array}{l}0.28 \\
0.55\end{array}$ & $\begin{array}{l}.006 \\
.007\end{array}$ & 2.37 * \\
\hline
\end{tabular}

${ }^{*} p<.01$

hypothesis that the two forearms act as independent detectors. The single exception (subject C.G. at AT $=32^{\circ} \mathrm{C}$, temperature change $=-0.3^{\circ} \mathrm{C}$ ) is probably due to a training effect, since that occurred on the first data collection session.

A further observation is that the difference between the detectability indices using one or two forearms is independent of stimulus intensities twice and four times larger than the lowest intensity used. The higher detectability for the two-forearm condition was also independent of the AT, including those to which the subject never completely adapted.

The relationship between area of stimulation, stimulus intensity, and detectability can be expressed in the following manner:

$$
\text { Given: } \quad \mathrm{S}=\mathrm{d}^{\prime}{ }_{2} / \mathrm{d}^{\prime}{ }_{1}
$$

where $\quad \mathrm{d}_{2}{ }_{2}=$ detectability index for the twoforearm condition at $-\Delta \mathrm{T}=\mathrm{t}^{\circ} \mathrm{C}$

and $\quad d^{\prime}{ }_{1}=$ detectability index for the oneforearm condition at $-\Delta \mathrm{T}=$ $2 \times \mathrm{t}^{\circ} \mathrm{C}$,

it can be said that if $S=1.0$, the relationship between stimulus intensity and area is such that these two variables are equally effective in producing a cool sensation of a given magnitude. Our calculations show that $S=1.10 \pm 0.18$ for the 30 pairs of comparisons, which indicate that area and intensity trade equally for the dimensions of the stimuli in this study.

In order to compare the form of curves representing the cool threshold as a function of AT obtained by classical psychophysical methods with the effect of AT on detectability, a constant value of $d^{\prime}$ of 1.0 was arbitrarily chosen (Wright, 1972). Curves were drawn from the stimulus intensities required to produce a d' of 1.0 as a function of AT, shown in Figure 3.

Detectability of $-\Delta T$ s decreased as ATs increased. This inverse relationship agrees with the results obtained when a classical method of limits was used to measure the cool threshold (Kenshalo, 1970). The forms of the curves are identical for the two-forearm condition compared to the single-forearm condition, and the two-forearm condition consistently showed smaller temperature changes necessary to produce a ' $d^{\prime}$ of 1.0. Stimulus intensities for the singleforearm condition were smaller than those obtained by Kenshalo (1970), using the classical method, probably due to the larger thermode used in this study $\left(18.4\right.$ vs. $14.4 \mathrm{~cm}^{2}$ ). Differences in the rates of cool-

Table 2

Parametric Significance Test Showing that Averaging of Data for the One-Forearm Condition Vs the Two-Forearm Condition Maintains the Initial Relationships (Subject: R.E., AT $=24^{\circ} \mathrm{C}$ )

\begin{tabular}{|c|c|c|c|c|c|c|c|c|}
\hline \multirow[b]{3}{*}{$\begin{array}{c}\text { Temperature } \\
\text { Change }\end{array}$} & \multirow[b]{3}{*}{ Condition } & \multirow{2}{*}{\multicolumn{2}{|c|}{ Probability }} & \multicolumn{2}{|c|}{ Trials } & \multirow[b]{3}{*}{$\mathrm{d}^{\prime}$} & \multirow[b]{3}{*}{ Variance } & \multirow[b]{3}{*}{ G Test } \\
\hline & & & & & Without & & & \\
\hline & & $\begin{array}{c}\text { Correct } \\
\text { Rejection }\end{array}$ & Misses & $\begin{array}{l}\text { With Stimu- } \\
\text { lation }\end{array}$ & $\begin{array}{l}\text { Stimu- } \\
\text { lation }\end{array}$ & & & \\
\hline \multirow{3}{*}{$-0.075^{\circ} \mathrm{C}$} & $\begin{array}{l}\text { Left } w / \text { Right } \\
\text { Left }\end{array}$ & $\begin{array}{l}.826 \\
.736\end{array}$ & $\begin{array}{l}.158 \\
.260\end{array}$ & $\begin{array}{l}247 \\
250\end{array}$ & $\begin{array}{l}253 \\
250\end{array}$ & $\begin{array}{l}1.94 \\
1.27\end{array}$ & $\begin{array}{l}.009 \\
.007\end{array}$ & $5.27^{*}$ \\
\hline & $\begin{array}{l}\text { Right w/Left } \\
\text { Right }\end{array}$ & $\begin{array}{l}.847 \\
.746\end{array}$ & $\begin{array}{l}.151 \\
.230\end{array}$ & $\begin{array}{l}249 \\
248\end{array}$ & $\begin{array}{l}251 \\
252\end{array}$ & $\begin{array}{l}2.05 \\
1.39\end{array}$ & $\begin{array}{l}.009 \\
.007\end{array}$ & $5.10^{*}$ \\
\hline & $\begin{array}{l}\text { Average Two } \\
\text { Average One }\end{array}$ & $\begin{array}{l}.837 \\
.741\end{array}$ & $\begin{array}{l}.155 \\
.245\end{array}$ & $\begin{array}{l}248 \\
251\end{array}$ & $\begin{array}{l}252 \\
249\end{array}$ & $\begin{array}{l}1.99 \\
1.33\end{array}$ & $\begin{array}{l}.009 \\
.007\end{array}$ & $5.18^{*}$ \\
\hline
\end{tabular}

${ }^{*} p<.001$ 

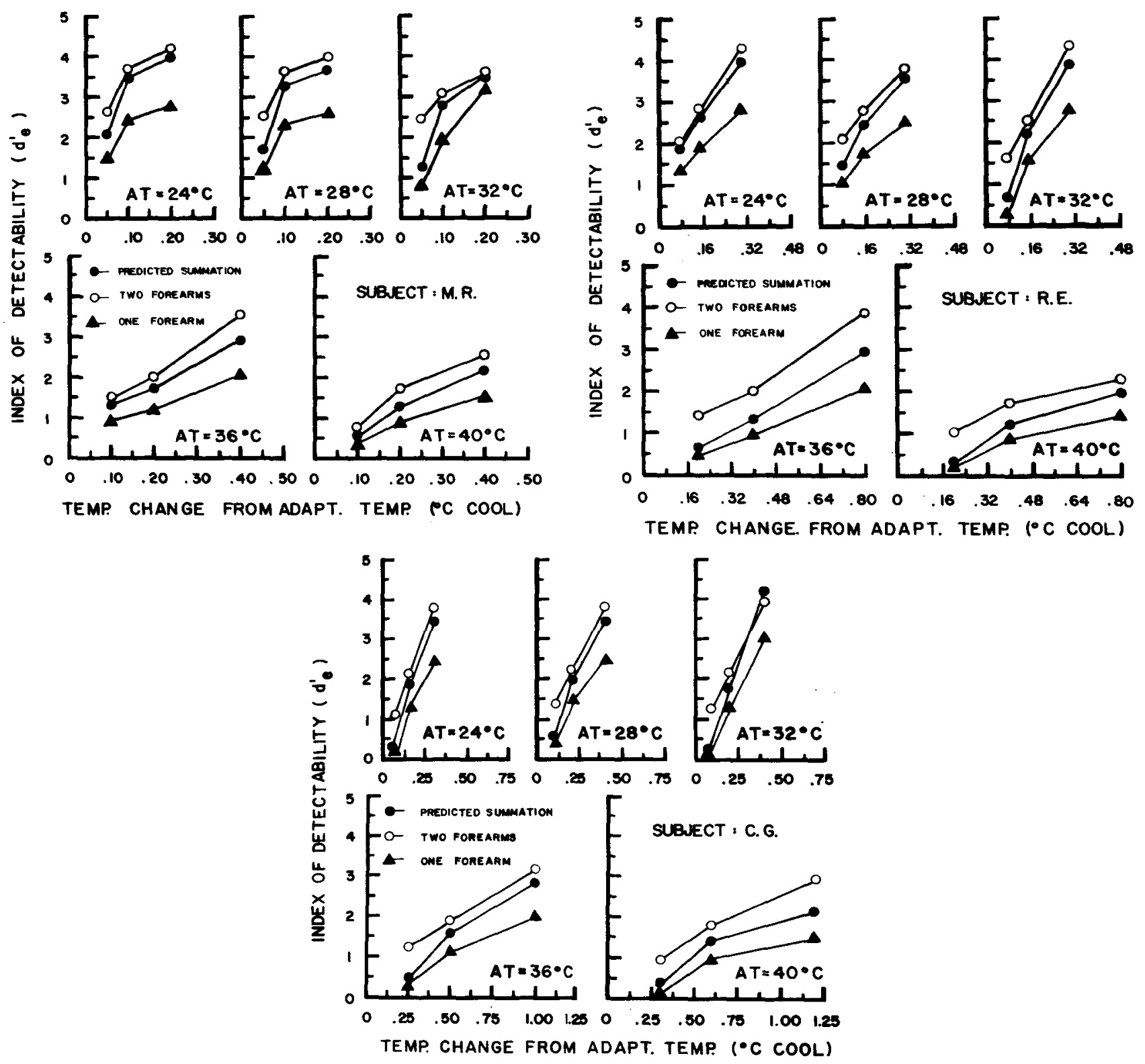

Figure 2. The detectability indices for each of the three subjects to thermal stimuli presented from the five ATs. Note that the subjects differed markedly in their sensitivity to $-\Delta \mathrm{Ts}$, hence their measurements could not be combined. Measurements of d's for the $R$ and $L$ for the $R L$ and $L R$ conditions were averaged. The spatial summation predicted was obtained from the integration model proposed by Green and Swets (1966) for multiple observations. (a) Subject M.R., (b) subject R.E., (c) subject C.G.

ing used $\left(1^{\circ} \mathrm{C}\right.$ vs. $\left.0.3^{\circ} \mathrm{C} / \mathrm{sec}\right)$ probably had little effect in producing this difference (Molinari, Greenspan, \& Kenshalo, Note 2).

It is interesting to note that at high ATs the slopes of the curves of this study mimic the one reported as a "change" curve in the classical psychophysical experiment (Kenshalo, 1970). Since the experimenter did not insist, in the instructions to the subjects, that only "cool" sensation should be rated, it appears that the subjects were attending to a change in sensa- tion rather than to the quality "cool." This sensory phenomenon of "change" also summed across area like "cool" sensations.

\section{Phenomenological Note}

During the subject training and the equipment calibration phase of this experiment, a serendipitous observation was made by two of the subjects. Even though the current controllers that energized the thermodes were triggered simultaneously, the com- 


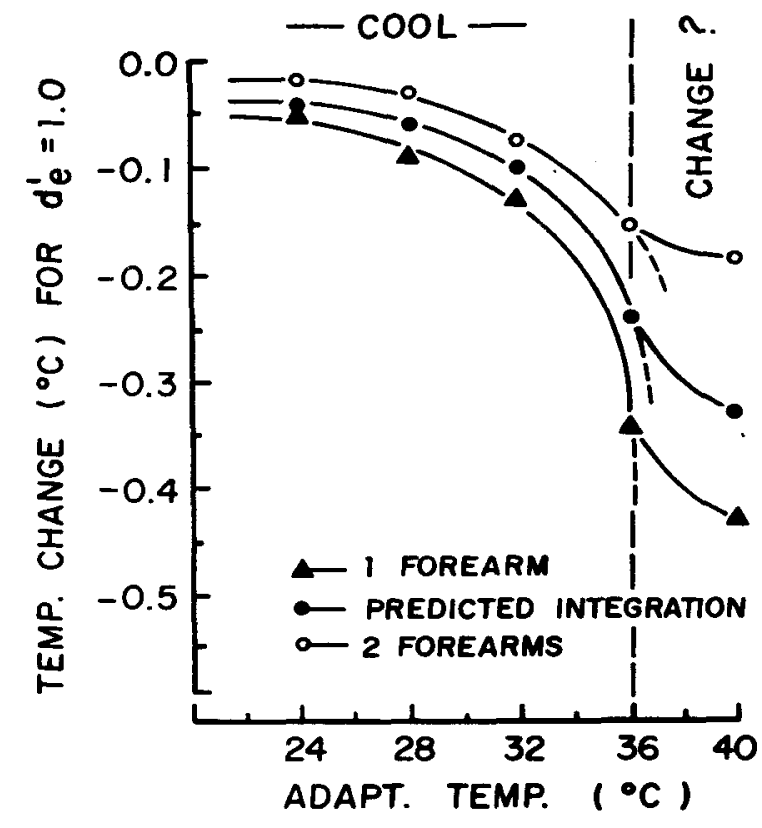

Figure 3. Isodetectability curves constructed from calculation of $-\Delta T$ corresponding to a constant detectability level of d' of 1.0 across all adapting temperatures. The rate of stimulation was $1^{\circ} \mathrm{C} / \mathrm{sec}$, and the areas of stimulation were $18.4 \mathrm{~cm}^{2}$ on each forearm.

pensating circuit that adjusted the ramps of the temperature changes introduced a slight delay in the onset of the temperature change of one thermode. As the onset difference between the two thermodes was decreased to about $250 \mathrm{msec}$, the subjects reported an apparent "movement" of the cool sensation from one forearm, across the body midline, to the other forearm. While no systematic study of this observation was attempted, this thermal "phi" persisted until the interstimulus onset interval decreased to less than $100 \mathrm{msec}$. This observation is similar to the ones described as vibratory "phi" (Geldard, 1961; Sherrick, 1968), as the haptic apparent movement produced by electrocutaneous pulses (Rosner, 1961), and the thermal heat motion reported by Békésy (1962). However, to date, we have seen only one report in which "movement" of a tactile sensation transversed the body midline (Békésy, 1967).

Once the onsets of the two thermal stimulators were calibrated and the external triggering of our oscilloscopes showed an onset coincidence within $0.1 \mathrm{msec}$, the thermal "phi" was no longer reported by any of the subjects. All the data reported in this study were collected following completion of our calibration procedure. Throughout the experiment, the subjects reported a completely "fused" thermal sensation always localized on the side to which they attended.

\section{DISCUSSION}

Thresholds determined by traditional psycho- physical procedures, such as the method of limits or constant stimuli, are held to be influenced by nonsensory variables such as attitudinal and response biases (Green \& Swets, 1966). For this reason, a rating signal detection method was employed, since this method distinguishes the effects of emotionalaffective components from the sensory components. It is clear from the results that the method is a reasonable procedure for use in the thermal sense and the data readily fit the theoretical model of detectability originally put forth by Tanner and Swets (1954). The normal deviate plots appeared as straight lines with a slope of unity, thus providing a simple graphical test of the normal distribution and equal variance model.

The most remarkable observation is that the phenomenon proposed in the original hypothesis was consistently evident, not only across the experimental conditions (ATs and stimulus intensities), but also across the subjects. While the subjects showed different sensitivities to the thermal stimuli, the forms of the detectability curves as a function of stimulus intensity were markedly similar for the three subjects.

The fact that the three male subjects were significantly more sensitive to dextral than to sinistral $-\Delta T$ s was unexpected. Based on the work of Ghent (1961) and Weinstein (1962, 1968; Weinstein \& Sersen, 1961) on the tactile sense, a greater sensitivity on the nondominant side might have been predicted. However, our results clearly indicate a greater dextral sensitivity even though one subject was sinistral.

The nonlinear relationship between spatial summation, $+\Delta \mathrm{T}$ intensities, and areas led Herget et al. (1941) and later researchers (Kenshalo, Decker, \& Hamilton, 1967; Marks, 1971; Marks \& Stevens, 1973) to suggest a two-stage mechanism for spatial summation of warmth. These stages represent two loci of convergence of sensory impulses. Thus, small areas $\left(1-5 \mathrm{~cm}^{2}\right)$ may be innervated by nerve endings (or receptors) whose branches converge on a single stem axon near the periphery. However, Duclaux and Kenshalo (1973) found that the net contribution of several cool sensitive spots within a single receptive field of a cold fiber was occlusion, illustrated by the fact that the peak frequency of activity in the fiber innervating two spots, for instance, was no larger when two spots were stimulated than when a more sensitive spot was stimulated alone. Thus, a peripheral summation mechanism is not supported.

The conclusions of Herget et al. (1941) regarding the central component of spatial summation appear reasonable. However, the use of single areas of increasing sizes could yield findings that result from simple nonlinear factors in the physics of temperature conductance in the tissue of different areas or effects that result from the differences 
in the amount of vascularization. More recent evidence seems to indicate that stimulation of adjacent areas across the midline (forehead and back) yields data that support the existence of a central mechanism for summation of warming (Banks, 1973; Marks \& Stevens, 1973). It is not clear, however, whether the possibility of thermal gradient or isotherm (Kenshalo, 1970) interactions has been eliminated, especially when the two areas are close to each other on the forehead. The conclusion that summation of warmth on the back must be central because it does not respect dermatome boundaries is questionable in view of the considerable overlap exhibited by the innervation of adjacent dermatomes (Truex \& Carpenter, 1969).

The results of Hardy and Oppel (1937), who found a lower threshold for $+\Delta \mathrm{Ts}$ when applied simultaneously to the backs of the two hands than when applied to either hand alone, constitute convincing evidence in support of a central spatial summation for $+\Delta T s$ as do the results of this investigation for $-\Delta \mathrm{Ts}$.

The mechanism by which thermal stimuli summate over area appears to be somewhat different for + than for $-\Delta$ Ts. As the intensity of supraliminal $+\Delta T$ s increases, the contribution of area diminishes. As a result, estimates of the magnitude' of the warm sensations produced by $+\Delta T$ s applied to different areas converged at $a+\Delta \mathrm{T}$ near the pain threshold (Marks \& Stevens, 1973; Stevens \& Marks, 1971). The fact that spatial summation was as large as supraliminal $-\Delta T$ intensities as for near-threshold intensities suggests that the contribution of area is constant across intensity, at least in the range of $-\Delta T$ s used in the present study. Based on this, we can speculate that psychometric functions of magnitude estimates of cool sensations for increasing intensities of $-\Delta T$ s applied to several areas will probably have a common exponent rather than exponents that are inversely related to area, as with $+\Delta \mathrm{Ts}$.

The first possible locus for integration of thermal information from bilateral sites is in the dorsal horn of the spinal cord. Recent evidence suggests that the dorsal horn is not only a collector and dispatcher of afferent (and efferent) information, but also an integrator, selector, decision maker, and discriminative filter of incoming information and outgoing sensory intelligence (Wall, 1973).

The interaction of bilaterally symmetrical thermal stimulation sites may occur by way of transcommissural interneurons of the type described in the spinal cord by Rēthelyi and Szentàgothai (1973). Hellon and Mitchell (1975) found that of all the spinal thermosensitive units that responded to either warm or cool stimuli applied to either or both sides of the scrotum of the rat, none responded solely to contralateral stimulation. Most of the units found responded to either contra- or ipsilateral stimuli, few solely to ipsilateral stimulation alone. These results indicate that the bilateral responses occur as a result of the transfer of information across the midline at the spinal level. The possibility of transfer across the body midline at levels higher in the CNS cannot be excluded, however.

The notion that signals do not, in general, travel along isolated and private lines but do affect each other in numerous ways through a parallel or "crosstalk" interaction is acceptable, though factual evidence is lacking. The evidence presented here suggests that central mechanisms can and do account for the spatial summation of cool stimuli, when such stimuli are presented bilaterally at symmetrical sites.

\section{REFERENCE NOTES}

1. Chatt, A. B. Response and receptive field properties of thermal sensitive cells recorded from the cat cortex. Doctoral dissertation, Florida State University, in preparation.

2. Molinari, H. H., Greenspan, J. D., \& Kenshalo, D. R. Rate of temperature change and sensation magnitude. In preparation.

\section{REFERENCES}

BANKs, W. P. Reaction time as a measure of summation of warmth. Perception \& Psychophysics, 1973, 13, 321-327.

BÉkÉsy, G. voN. Lateral inhibition of heat sensation on the skin. Journal of Applied Physiology, 1962, 17, 1003-1008.

BékÉsy, G. von. Sensory inhibition. Princeton, N.J: Princeton University Press, 1967.

Dallenbach, K. The temperature spots and end-organs. American Journal of Psychology, 1927, 39, 402-427.

DodT, E., \& ZotTERMAN, Y. Mode of action of warm receptors. Acta Physiologica Scandinavica, 1952, 26, 345-357.

Duclaux, R., \& Kenshalo, D. R. Cutaneous receptive fields of primate cold fibers. Brain Research, 1973, 55, 437-442.

GELDARD. F. A. Cutaneous channels of communication. In W. A. Rosenblith (Ed.), Sensory communication. Cambridge, Mass: MIT Press, 1961.

Ghent, L. Developmental changes in actual thresholds on dominant and nondominant sides. Journal of Comparative and Physiological Psychology, 1961, 54, 670-673.

Gourevitch, V., \& Galanter, E. A significance test for one parameter isosensitivity functions. Psychometrika, 1967, 32, 25-32.

GREEN, D. M., \& SwETs, J. A. Signal detection theory and psychophysics. New York: Wiley, 1966.

HARDY, J. D., \& OPPEL, T. W. Studies in temperature sensation. III. The sensitivity of the body to heat and the spatial summation of the end organ responses. Joumal of Clinical Investiga. tions, 1937, 16, 533-540.

HARDY, J. D., \& OPPEL, T. W. Studies in temperature sensation. IV. The stimulation of cold sensation by radiation. Joumal of Clinical Investigations, 1938, 17, 771-777.

Hellon, R. F., \& Mrtchell, D. Convergence in the thermal afferent pathway in the rat. Journal of Physiology, 1975, 248, 359-376.

HeNSEL, H. Cutaneous thermoreceptors. In H. Autrum, R. Jung, W. R. Loewenstein, D. M. McKay, \& H. L. Teuber (Eds.), 
Handbook of sensory physiology (Vol. 2) Somatosensory system (A. Iggo, Ed.). Berlin: Springer-Verlag, 1973.

Hensel, H., \& Zotterman, Y. Quantitative Beziehungen zwischer der Entlandung einzelner Kaltefasern und der Temperatur. Acta Physiologica Scandinavica, 1951, 23, 291-319.

Herget, C. M., Granath, L. P., \& Hardy, J. D. Warmth sense in relation to the area of the skin stimulated. American Journal of Physiology, 1941, 135, 20-26.

Hollander, M., \& Wolfe, D. A. Nonparametric statistical methods. New York: Wiley, 1973.

Kenshalo, D. R. Psychophysical studies of temperature sensitivity. In J. W. Neff (Ed.), Contributions to sensory physiology. New York: Academic Press, 1970.

Kenshalo, D. R. The cutaneous senses. In J. W. Kling \& L. A. Riggs (Eds.), Woodworth and Schlosberg's experimental psychology (Vol. 1, 3rd ed.). New York: Holt, Rinehart, \& Winston, 1972.

Kenshalo, D. R., \& Bergen, D. C. A device to measure cutaneous temperature sensitivity in human and subhuman species. Journal of Applied Physiology, 1975, 39, 1038-1040.

Kenshalo, D. R., Decker, T., \& Hamilton, A. Spatial summation on the forehead, forearm, and back produced by radiant and conducted heat. Journal of Comparative and Physiological Psychology, 1967, 63, 510-515.

Kreisman, N. R., \& Zimmerman, I. D. Representation of information about skin temperature in the discharge of single cortical neurons. Brain Research, 1973, 55, 343-353.

MARKs, L. E. Spatial summation in relation to the dynamics of warmth sensation. International Journal of Biometeorology, $1971,15,106-110$.

Marks, L. E., \& Stevens, J. C. Spatial summation of warmth: Influence of duration and configuration of the stimulus. American Journal of Psychology, 1973, 86, 251-267.

Ogilvie, J. C., \& Creelman, C. D. Maximum-likelihood estimation of receiver operating characteristic curve parameters. Journal of Mathematical Psychology, 1968, 5, 377-391.

Pastore, R. E., \& Scherrer, C. J. Signal detection theory: Considerations for general applications. Psychological Bulletin, 1974, 81, 945-958.

RÈthelyi, M., \& SzentágothaI, J. Distribution and connections of afferent fibers in the spinal cord. In H. Autrum, R. Jung,
W. R. Loewenstein, D. M. McKay, \& H. L. Teuber (Eds.), Handbook of sensory physiology (Vol. 2) Somatosensory system (A. Iggo, Ed.). Berlin: Springer-Verlag, 1973. Pp. 207-252.

RoSNER, B. S. Neural factors limiting cutaneous spatiotemporal discriminations. In W. A. Rosenblith (Ed.), Sensory communication. Cambridge, Mass: MIT Press, 1961.

SHERRICR, C. E. Studies of apparent tactual movement. In D. R. Kenshalo (Ed.), The skin senses. Springfield, Ill: Thomas, 1968. Pp. 330-342.

Stevens, J. C., \& Marks, L. E. Spatial summation and the dynamics of warmth sensation. Perception \& Psychophysics, 1971, 9, 391-398.

Stevens, J. C., \& Stevens, S. S. Warmth and cold: Dynamics of sensory intensity. Journal of Experimental Psychology, 1960, 60, 183-192.

TANNER, W. P., \& Swets, J. A. A decision-making theory of visual detection. Psychological Review, 1954, 61, 401-409.

Truex, R. C., \& CaRPenter, M. B. Human neuroanatomy (6th ed.). Baltimore, Md: Williams \& Wilkins, 1969.

WALL, P. D. Dorsal horn electrophysiology. In H. Autrum, R. Jung, W. R. Loewenstein, D. M. McKay, \& H. L. Teuber (Eds.) Handbook of sensory physiology (Vol. 2) Somatosensory system (A. Iggo, Ed.). Berlin: Springer-Verlag, 1973. Pp. 253-270.

Weinstein, S. Tactile sensitivity of the phalanges. Perceptual and Motor Skills, 1962, 14, 351-354.

Weinstein, $S$. Intensive and extensive aspects of tactile sensitivity as a function of body part, sex, and laterality. In $D$. R. Kenshalo (Ed.), The skin senses. Springfield, Ill: Thomas, 1968. Pp. 195-218.

Weinstein, S., \& Sersen, A. E. Tactual sensitivity as a function of handedness and laterality. Journal of Comparative and Physiological Psychology, 1961, 54, 665-669.

WRIGHT, A. A. Psychometric and psychophysical hue discrimination functions for the pigeon. Vision Research, 1972, 12, $1447-1464$

(Received for publication October 4, 1976; revision received February 21, 1977.) 